REVIEW

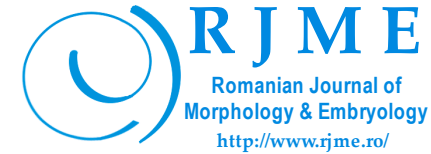

\title{
Current classification systems and standardized terminology in cytopathology
}

\author{
TIBOR MEZEI \\ Department of Pathology, George Emil Palade University of Medicine, Pharmacy, Science, and Technology of Târgu Mureş, \\ Romania
}

\begin{abstract}
The history of classification systems and the search for a unified nomenclature in cytopathology spans several decades and expresses the preoccupation of all those involved to make cytopathology a reliable diagnostic tool and a trusted screening method. Early classification schemes, applicable to exfoliative and aspiration cytology, attempted to set some basic standards for how non-gynecological cytopathology findings should be reported. While useful in establishing some basic guidelines, these were not specific to the various fields of nongynecologic cytopathology, often burdened with specific problems. Cytopathology has evolved tremendously in the last couple of decades, undoubtedly boosted by the emergence of various classification schemes that, more than ever, are based on evidence gathered by professionals across the globe. The benefit of classification systems and standardized nomenclature in cytopathology is to provide useful, clear, and clinically relevant information for clinicians and ultimately to provide the best patient care. Standardized reporting systems make cytopathology reports more meaningful and robust. It now became standard that these include by default elements, such as adequacy criteria, diagnostic groups, risk of malignancy (ROM), and recommendations for patient management. In this brief review, we attempted to summarize how these classification schemes emerged and how they are reshaping the landscape of diagnostic cytopathology.
\end{abstract}

Keywords: cytopathology, cytology, classification systems, standardization, nomenclature.

\section{Introduction}

In cytopathology and histopathology, and medicine in general, there is an ongoing pursuit to classify better and categorize more accurately various disease entities. The purpose of this pursuit is the case of cytopathology is to deliver useful, clear, and clinically relevant information for clinicians to provide the best patient care. This endeavor encompasses the definition of pertinent terminology and nomenclature. By definition, terminology refers to the sum of terms used in a particular technical application within a subject area, profession, or theory; on the other hand, nomenclature is choosing names for things, especially in a science or other discipline.

Cytopathology has evolved tremendously in the last couple of decades, undoubtedly boosted by the emergence of various classification schemes that, more than ever, are based on substantial evidence, gathered, and interpreted by professionals across the world. In order to make cytopathology reports more meaningful and robust, standardized reporting systems were developed. Common elements are the adequacy criteria, diagnostic categories with associated (predicted) risk of malignancy (ROM), and recommendation or optional educational notes. Most classifications are sufficiently dynamic to incorporate new changes into revision, based on newly acquired evidence [1].

In this brief review, an attempt was made to summarize the circumstances of how these classification schemes emerged and the way they are reshaping the landscape of diagnostic cytopathology. Some historical context was added with comments on current applications. It is acknowledged that such an undertaking does not address every detail of the presented classification systems as more details are presented in relevant bibliographic sources.

Firstly, we consider the mother of all cytopathology classifications (the Bethesda System in cervical cytology) and then the various other cytopathology fields where classification schemes are currently being used or have been recently introduced. The order they are presented is somewhat arbitrary; nevertheless, a chronological order was followed.

\section{$\square$ The rationale for standardized classification and reporting systems}

A classification system's birth usually stems from the necessity to have a common language for pathologists and clinicians. Having a common ground greatly facilitates communication, quality assurance, research, and education. Most, if not all, modern classification systems now include ROM for a given diagnostic category that can aid optimal patient management. Regarding quality assurance, laboratories implementing standardized classification and reporting systems are able to verify the accuracy of their diagnosis by comparing their data to established metrics (category distribution, category ratio, etc.) and other laboratories [2-4]. Without standardized reporting, some of the more rigorous activities associated with best practices would be impossible - activities such as data comparison, internal and external quality control, and research. Paradoxically, currently used tiered classification systems are indispensable

This is an open-access article distributed under the terms of a Creative Commons Attribution-NonCommercial-ShareAlike 4.0 International Public License, which permits unrestricted use, adaptation, distribution and reproduction in any medium, non-commercially, provided the new creations are licensed under identical terms as the original work and the original work is properly cited. 
for their refining and revision, as their strict application enabled research groups to gather more clinical data.

To increase the value of clinical applicability, modern classification systems were, and are, developed with the input from the clinicians. The development of current classification systems was done by international committees composed of representatives from various expert groups originating from multiple countries. Additionally, further information was obtained from discussion groups and online surveys. Some of the more prominent entities that greatly facilitated the establishment of various classification systems are government agencies [National Cancer Institute (NCI)], professional organizations as The American Society of Cytopathology (ASC), The Papanicolaou Society, and The International Academy of Cytology (IAC), that, together with local societies, coordinated the development of the classification and reporting systems in use today.

\section{Cervical cytology, the Bethesda System}

The use of cervical cytology as a screening tool in the prevention of cervical cancer has a long history and accounting for all those who contributed to its development is outside the scope of this article. Nevertheless, without bias, some names need to be mentioned. One was George Papanicolaou, an American scientist with Greek origins, who in 1928 published an article about the importance of cervical smear in the diagnosis uterine cervix cancer [5]. Despite gaining the academic and health community's attention much later, undoubtedly, this acted as a spark that led to the foundation of cytopathology as a science with enormous implications in public health $[6,7]$. No wonder that Dr. Papanicolaou is considered the godfather of cervical cytology, not only for his extensive pioneer work in the field, but also because he contributed significantly to the recognition of cytopathology as an indispensable diagnostic tool in everyday clinical practice. We must give credit to a Romanian pathologist, namely Aurel Babeş [8], who, a year earlier (Figures 1 and 2), independently published the same conclusion: a simple cervical smear is suitable for the detection of cervical cancer or its premalignant states. He later stated that the method is diagnostic of cervical cancer. Rumor has it that Papanicolaou's Nobel Award was rejected because he did not cite Babeş' previously published paper, a statement that needs further confirmation $[9,10]$.

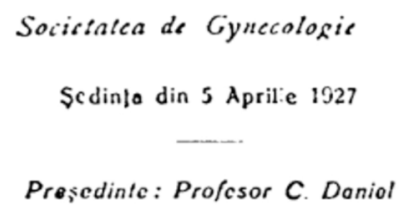

I.

Diagnosticul cancerului colului uterin prin frotiu

$$
\text { de C. Daniel şi A. Babes }
$$

Figure 1 - Title page of the presentation by Dr. Aurel Babeş, co-authored by Professor Constantin Daniel, on the diagnosis of cervical cancer from smears (Bucharest Society of Gynecology on April 5, 1927).
Glinique gynécologique de Bucarest

(Professeur C. Daniel).

\section{DIAGNOSTIC}

\section{DU CANCER DU COL UTÉRIN}

PAR LES FROTTIS

\author{
Par A. BABÈS \\ Maitre de Conférences à la Faculté de Médecine \\ de Bucarest.
}

Le diagnostic précoce du cancer du col utérín, comme d'ailleurs du cancer en général, est basé sur l'examen histopathologique de la biopsie faite au niveau des lésions.

Dans l'état actuel de nos connaissances, il existe deux caractères histopatbologiques permettant le diagnostic précoce du cancer : l'hétérołypie, c'està-dire l'envahissement des éléments épithéliaux en prolondeur, et l'atypie, la modification des cellules épithéliales.

Figure 2 - Title of the article by Dr. Aurel Babeş published in Presse Médicale ("Diagnosis of cancer of the uterine cervix by means of smears", 1928).

The seventies and eighties saw a remarkable decrease in deaths attributable to cervical cancer that caused a widespread and potentially uncritical acceptance of the screening method, more and more laboratories hastily joined the race. The initially too silent alarm bell rang in the form of several articles describing the failure of the cervicovaginal smear in preventing the development of invasive cancer of the uterine cervix [11-13] gaining, again, little reaction from the academic community. It was not until 1987 when an article published by Walt Bogdanich in The Wall Street Journal stirred nation-wide attention in the United States. Bogdanich, an investigative journalist, shed light on the laboratories' failure to identify cervical cancer in young women, attracting a great deal of attention $[14,15]$. The results of his publications were palpable, the Congress of the United States promulgated a Law, in 1988, known as the Amendment to the Clinical Laboratory Improvement Act (CLIA '88), governing the practice of gynecologic cytology in the United States [16-18]. CLIA ' 88 had far-reaching implications and eventually resulted in cytopathology, particularly cervicovaginal smears, becoming the object of intense scrutiny and legal proceedings against pathologists and laboratories for allegedly missing to detect cancer, painting black an otherwise very successful laboratory test. Even though the mortality associated with cervical cancer has decreased significantly due to the common availability of the Pap test at that time, criticism of the test has sensitized the medical profession and US government agencies on the necessity for quality assurance measures in cytopathology. One of the most crucial quality assurance parameters refers conveying the cytopathology findings to the clinician in terms that are obvious and have clinical meaning. The often ambiguous and varied terminology that existed at the time created an imperative need for a new nomenclature. 
Within the above historical perspective, the Division of Cancer Prevention and Control, NCI convened at the National Institutes of Health (NIH) campus in Bethesda, Maryland, on December 12-13, 1988 to review existing terminology and recommend effective reporting terminology [19]. This meeting materialized in The Bethesda System for Reporting Cervical Cytology (shortly The Bethesda System or TBS) that even after more than 30 years stands its ground and is used worldwide today. Probably one of the most significant achievements of TBS was the creation of a standardized model soon to be followed by other fields of cytopathology. Many concepts laid down in TBS were later incorporated in other classification schemes, including the requirements of the CLIA ' 88 [20].

Thus, TBS paved the way for standardized and uniform reporting systems in cytopathology. Its goals can be theoretically applied to any cytopathology classification scheme; these include $(i)$ the ability to transmit clinically relevant information from the laboratory to the clinicians; (ii) be uniform and reproducible across various pathologists and laboratories, but also reasonably flexible to be adopted in different laboratories across the world; (iii) reflect the most current understanding of disease entities it is aimed at detecting. The latest edition of TBS Atlas contains the concepts, definitions, and current terminology, accompanied by excellent images to help understand the text [21].

A detailed description of TBS, which is applicable to both conventional and liquid based cytological preparations, is beyond the scope of this article (Table 1), some aspects, however, merit attention [22-25].

Table 1 - The main diagnostic categories of the 2014 Bethesda System for Reporting Cervical Cytology (see comments in text)

Negative for intraepithelial lesion or malignancy:

- May include reactive changes, infections, therapy-related states, etc.

Other:

- Benign endometrial cells in women 45 or older.

Epithelial cell abnormalities:

- Squamous cells (ASC-US, ASC-H, LSIL, HSIL, etc.);

- Glandular cells (AGC, AdC, etc.).

AdC: Adenocarcinoma; AGC: Atypical glandular cells; ASC-H: Atypical squamous cells cannot exclude HSIL; ASC-US: Atypical squamous cells of undetermined significance; HSIL: High-grade squamous intraepithelial lesion; LSIL: Low-grade squamous intraepithelial lesion.

Due to the difficult reproducibility of the cytological cervical intraepithelial neoplasia (CIN) II category, TBS merged CIN II and CIN III into high-grade squamous intraepithelial lesion (HSIL), separating it from the lowgrade squamous intraepithelial lesion (LSIL) [26, 27]. Also, the word 'lesion' replaced 'neoplasia', with obvious psychological benefits. The reporting of benign endometrial cells changed in the last revision, reflecting the incorporation of data accumulated since its introduction. It is now recommended that benign endometrial cells should be reported in women aged 45 or older. The application of TBS provides a laboratory some insights into quality, achieved by monitoring such metrics as the atypical squamous cells of undetermined significance (ASC-US) rate, ASC-US:squamous intraepithelial lesion (SIL) ratio [28].

\section{a Thyroid cytology, the Bethesda System}

The Bethesda System for Reporting Thyroid Cytopathology (TBSRTC) was conceived in 2007 after several months of preparations. This was a much-needed step in standardizing the terminology since this varied significantly among laboratories, creating confusion and making it difficult to share data among different institutions. It was also the first attempt, and as time has proven, quite a successful one, to create a standardized classification system applicable to fine-needle aspiration (FNA) cytology specimens. TBSRTC is organized in six categories (Table 2), which remained unchanged in the second edition; definitions, morphological criteria, and explanatory notes have been refined.

Table 2 - The diagnostic categories of The Bethesda System for Reporting Thyroid Cytopathology (TBSRTC)

I. Nondiagnostic of unsatisfactory

II. Benign

III. AUS / FLUS

IV. Follicular neoplasm or suspicious for a follicular neoplasm

$\mathrm{V}$. Suspicious for malignancy

VI. Malignant

AUS: Atypia of undetermined significance; FLUS: Follicular lesion of undetermined significance.

This classification scheme is now widely used and was quickly adopted worldwide. Significantly aids the communication and comparison of data among multiple laboratories. TBSRTC diagnostic categories are relatively straightforward and are excellently described and explained in the second edition of the Atlas [29]. Most have clear cut clinical management protocols, except the two so-called "grey-zone" categories, namely (i) Category III - atypia of undetermined significance (AUS)/follicular lesion of undetermined significance (FLUS) and (ii) Category IV - follicular neoplasm/suspicious for follicular neoplasm. The former is reserved for cases with atypia that is insufficient for inclusion in higher categories, yet it is more marked than changes attributable to benign changes, while the latter represents a screening test rather than a diagnostic test in the case of follicular patterned lesions [30]. These are the cases that probably would benefit most from molecular studies. As for the nomenclature used for category III, both "atypia of undetermined significance (AUS)" or "follicular lesion of undetermined significance (FLUS)" may be used; however, it is preferred that only one should be used consistently, rather than interchangeably.

An essential aspect of TBSRTC is that a ROM value is assigned to each diagnostic category, aiding the referring clinician in patient management. When interpreting the ROM values, inherently to the calculation method, one needs to take into consideration that some bias occurs. Most important is the verification bias that artificially increases the ROM values in diagnostic categories that are less likely to recommend surgical resection. Without surgical resection, the histopathological examination of such nodules is less likely.

The newly described entity of non-invasive follicular thyroid neoplasm with papillary-like nuclear features (NIFTP) has implications for the ROM [31], as seen in Table 3. When calculating the ROM values, one needs to consider that the first three categories harbor selection 
bias since a relatively few patients with thyroid nodules assigned to these categories undergo surgery. Assuming that all unresected thyroid nodules are benign would most probably result in an underestimated ROM, therefore the actual ROM is somewhere in between [29, 32, 33].

Table 3 - Implied ROM assigned to each diagnostic category before and after the introduction of the NIFTP histological diagnosis

\begin{tabular}{ccc}
\hline Bethesda category & Initial ROM & ROM after NIFTP \\
\hline I. & $5-10$ & $5-10$ \\
\hline II. & $0-3$ & $0-3$ \\
\hline III. & $10-30$ & $6-18$ \\
\hline IV. & $25-40$ & $10-40$ \\
\hline V. & $50-75$ & $45-60$ \\
\hline VI. & $97-99$ & $94-96$
\end{tabular}

NIFTP: Non-invasive follicular thyroid neoplasm with papillary-like nuclear features; ROM: Risk of malignancy.

As for quality control measures, the AUS category rate should not exceed $10 \%$ to avoid overdiagnosis of benign thyroid nodules as atypical. Despite some limitations, TBSRTC remains one of the most robust classification schemes used in FNA cytology, which became the flagship of other tiered classification systems for this type of specimens.

\section{ㅁ Urinary cytology, the Paris System}

Dr. Papanicolaou was also among the pioneers of urinary cytopathology, convinced that exfoliated cells in the urine might be used to detect urinary tract malignancies. He was among the first to signal the challenges facing urinary cytology and the need for rapid fixation to avoid cellular degeneration. He also pioneered a classification scheme of five classes. Another prominent person was Leopold G. Koss whose contributions to cytopathology and to surgical pathology left everlasting footprints as well. One of his endeavors was to unite the relatively divergent disciplines, at that time at least, of cytopathology and histopathology, to the benefit of both. Dr. Koss argued that the early classification schemes in cytopathology were unclear and needed to be improved by fundamenting the terminology on histological diagnoses. No wonder that his descriptions used in urine cytology were heavily based on the histopathological classification and histomorphology of bladder cancer. He noted that high cellularity, nuclear hyperchromasia, irregular nuclear contours, and atypical chromatin texture were the hallmark of cancer [34]. Over the years, other classification schemes for urinary cytopathology were briefly used, such as those proposed by Murphy \& Ooms/Veldhuizen, and the Hopkins Template, prior to the now-used scheme was published [35-37]. These classification systems emerged in harmony with the histological classification used for bladder tumors. It is well known that some of the shortcomings of urinary cytopathology, particularly low sensitivity in detecting low-grade non-invasive lesions, make urinary cytology samples one of the more difficult specimens encountered in cytopathology [38-40]. Difficulties also arise from low cellularity of smears and pre-fixation cellular deterioration.

A standardized reporting system for urinary cytology was long-awaited by the cytopathology community. It finally took shape in 2013 at the $18^{\text {th }}$ International Congress of
Cytology (organized by the $I A C$ ) in Paris, hence its name [41].

The pathogenetic base of The Paris System (TPS) for Reporting Urinary Cytology is based on our current understanding of urothelial carcinoma (Table 4). The majority of bladder urothelial neoplasias are non-invasive papillary tumors, histologically categorized as low-grade urothelial carcinomas (LGUC). Despite having a good prognosis, they are associated with recurrence and progression to high-grade urothelial carcinomas (HGUC) in a proportion of cases. The rest of urothelial carcinomas are invasive tumors categorized histologically as HGUC with a worse prognosis. TPS also considered the intricate molecular changes and genetic evidence that indicates these two disease entities, one with better prognosis and one with a higher mortality rate, and, as said before, urine cytology has a high sensitivity for and is therefore primarily aimed at detecting HGUC, while having a poor sensitivity at the detection of LGUC [42].

Table 4 - Diagnostic categories of the Paris System

(TPS) for Reporting Urinary Cytology

1. Nondiagnostic / unsatisfactory

2. NHGUC

3. AUC

4. SHGUC

5. HGUC

6. LGUC

7. Other, primary or secondary malignancies or other lesions.

AUC: Atypical urothelial cells; HGUC: High-grade urothelial carcinoma; LGUC: Low-grade urothelial carcinoma; NHGUC: Negative for highgrade urothelial carcinoma; SHGUC: Suspicious for high-grade urothelial carcinoma.

According to TPS, specimens harboring at least 10 well preserved abnormal epithelial cells with a nuclear:cytoplasmic (N:C) ratio of $>0.7$ are designated as malignant. Cases with a $\mathrm{N}$ : C ratio less than that, when other cytological abnormalities are also present, fall into the categories of atypical or suspicious for malignancy. The problem of lowgrade lesion is also addressed, including the catheterized or washing specimens harboring larger epithelial groups secondary to instrumentation. An Atlas is available discussing in detail the diagnostic criteria, ROM, and patient management options [43].

\section{a Salivary gland cytology, the Milan System}

The idea of a tiered system in salivary gland FNA cytology was originally conceived in Boston, MA, in 2015 during the annual The United States and Canadian Academy of Pathology (USCAP) meeting. The soon to be created taskforce met in 2017, in Milan, Italy, during the European Congress of Cytology and established the initial framework that later materialized in The Milan System for Reporting Salivary Gland Cytopathology (MSRSGC) (Table 5) [44, 45]. At the time of its conception, no unified and widespread reporting system existed; nevertheless, salivary gland FNA was already an established preoperative diagnostic tool. The lack of a tiered classification system hampered the efficacy of the test, both as a screening tool and as a diagnostic one, given the unique problems the field of cytopathology presented [46-50]. 
Table 5 - The Milan System for Reporting Salivary Gland Cytopathology (MSRSGC): diagnostic categories

\begin{tabular}{l}
\hline I. Non-diagnostic \\
\hline II. Non-neoplastic \\
\hline III. AUS \\
\hline IV. Neoplasm: \\
A. Benign; \\
B. SUMP. \\
\hline V. SM \\
\hline VI. Malignant
\end{tabular}

AUS: Atypia of undetermined significance; SM: Suspicious for malignancy; SUMP: Salivary gland neoplasm of uncertain malignant potential.

MSRSGC shows high accuracy for the two most common salivary gland tumors, namely pleomorphic adenoma and Warthin's tumor. It was a multidisciplinary effort to provide an evidence-based classification and reporting system applicable to such a diverse and complex pathology as salivary gland lesions. This classification scheme incorporates several standards set by previous systems (the Bethesda System for thyroid, the Paris System for urinary cytopathology). The MSRSGC created a specific category named salivary gland neoplasm of uncertain malignant potential (SUMP) that includes lesions with indeterminate cytomorphology, many with basaloid features and worrisome nuclear atypia. Similarly to its predecessors, the various diagnostic categories have ROMs associated, making the classification system indispensable for making preoperative therapeutic decisions [51, 52]. Shortly thereafter, an Atlas with definitions, diagnostic criteria, and educational notes soon followed, helping the cytopathologists across the world to familiarize themselves with MSRSGC [53]. Since its publication, there are a plentiful of papers praising its utility in everyday practice. Many of the centers, where salivary gland FNA is practiced on a daily basis, attempted to retrospectively classify cases that were previously diagnosed according to non-standardized terminology, and the results speak for themselves [54-57]. Most studies substantiate its validity and diagnostic utility, encouraging its application in everyday practice to provide appropriate patient management [58-60]. Variations in risk stratification values (ROM) are occasionally observed among different publications, but this may well represent clinical practice differences or case number induced bias. The significance of MSRSGC can be summarized as necessary guidance in surgical planning and decision making.

\section{ㅁ Pancreatobiliary cytology}

Pancreatobiliary cytopathology is particularly tricky due to the variability of disease entities that may be encountered in this region, such as cysts, stromal neoplasms, and neuroendocrine tumors. This led to the inclusion of a relatively new concept within the neoplastic/benign category, the 'other' subgroup designated for lesions with uncertain malignant potential. The most recent classification scheme was first published in 2014, and it is called The Papanicolaou Society of Cytopathology System for Reporting Pancreaticobiliary Cytology. The proposed terminology scheme recommends six diagnostic categories: I. Nondiagnostic; II. Negative (for malignancy); III. Atypical; IV. Neoplastic: benign and other; V. Suspicious (for malignancy) and VI. Positive or malignant [61].
Association of precise ROM to each category, similarly to other classification systems, is not as straightforward and easy in pancreatobiliary cytology, as some of the categories contain various premalignant, neoplastic, and malignant lesions. Therefore, ROM is mostly applicable to pancreatic ductal adenocarcinoma, the most common malignancy of this organ. The shortly thereafter published Atlas contains a detailed description of each category, with diagnostic criteria, illustrations, and explanatory notes [62].

\section{Respiratory cytology}

Respiratory cytology includes a variety of specimens ranging from sputum, bronchial brushings, bronchial washings (bronchioloalveolar lavage), and FNA cytology. The first Guidelines of The Papanicolaou Society of Cytopathology System for Reporting Respiratory Cytology were published in $2016[63,64]$. The reporting scheme proposes a six-tiered system, of which the neoplastic category is constructed similarly to the above-mentioned reporting system for pancreatobiliary cytology. It includes the following six categories: I. Nondiagnostic; II. Benign; III. Atypical; IV. Neoplasm (A. Benign, B. Undetermined malignant potential); V. Suspicious for malignancy (SM); VI. Malignant. These diagnostic categories are especially important in the reporting of endobronchial ultrasoundguided fine-needle aspiration (EBUS-FNA), a method that gained increasing popularity for the diagnosis and staging of lung cancer [65-68].

Recent changes in the classification and nomenclature of lung tumors resulted in the abolition of the term 'bronchioloalveolar carcinoma'. Lesions with this type of growth pattern are termed adenocarcinoma in situ, minimally invasive adenocarcinoma, or invasive adenocarcinoma with a lepidic pattern, and, according to the World Health Organization (WHO), are based exclusively on resection specimens [69]. In these cases, whenever suspicious cytological signs are observed, a comment may be added to warn the clinician of such an adenocarcinoma component.

ROM for these categories, diagnostic criteria, definitions, and illustration are found in the Atlas with the same name [70].

\section{ㅁ Breast FNA biopsy cytopathology, the Yokohama System}

Breast fine-needle aspiration biopsy (FNAB) was extensively used worldwide as a preoperative diagnostic tool, however, with the advent of core-needle biopsy (CNB) its application seems to have decreased in recent years, partly due to the ability of CNB specimens to provide more information about the lesion being investigated, including the possibility to perform immunohistochemical studies. There is an ongoing debate about whether FNAB is needed if CNB is available and offers some indubitable advantages over the former. Compared to FNAB, CNB is a more aggressive intervention with a higher rate of complications, and also more expensive, nevertheless offers greater specificity than FNAB [71]. Although, in some centers, CNB completely replaced the evaluation of palpable and nonpalpable breast nodules/lesions, FNAB remains an essential diagnostic tool, especially in a low resource 
setting. Given nowadays' modern possibilities to perform molecular studies on cytology material, FNAB is also suitable for obtaining material to perform molecular studies $[72,73]$. There are several scenarios where breast FNAB is superior or may be the preferred diagnostic tool, even if CNB is readily available; such situations include cysts, abscesses, difficult to biopsy lesions, palpable lesions without imaging abnormality, or where CNB may be risky to perform, just to name a few.

Considering this, under the auspices of the $I A C$, in May 2016, a group of experts met at the International Congress of Cytology in Yokohama and laid the foundation for a reporting system applicable to breast FNAB, soon after that published in Acta Cytologica [74]. The Yokohama System has five categories: insufficient/inadequate; benign; atypical; suspicious for malignancy; malignant. To each category, a different ROM value (or range) is associated, much like the Bethesda System used in thyroid cytopathology. The recently published Atlas contains all the relevant information to successfully apply the Yokohama Reporting System [75].

\section{a Serous fluid cytopathology}

Serous fluid cytopathology, despite being one of the most common specimens processed by cytopathology laboratories, also lacked a uniform reporting terminology and system. Serous fluid effusions originate from either the pleural, pericardial, and peritoneal cavities, having various non-neoplastic and neoplastic causes. The particularities of this type of specimen include the frequently large volume of the collected liquid, the often-troubling mesothelial proliferations, the sometimes-variable cellular component, and the uniqueness of peritoneal washings, just to name a few.

In the footsteps of previously established reporting systems, with a collaborative effort, the $I A C$ and $A S C$ proposed a classification system in 2019 called The International System for Reporting Serous Fluid Cytopathology [76]. Based on current practice and previous classification systems, it includes the following five categories: non-diagnostic (ND); negative for malignancy (NFM); atypia of undetermined significance (AUS); suspicious for malignancy (SM), and malignant (MAL). The application of this classification system, in line with its predecessors, seems to fit well the clinical practice and meets the requirements it was designed for. There are already several publications that validated its usefulness, including studies with cytohistological correlations [7779]. As expected, an Atlas including the diagnostic criteria, illustrations and sample reports is on the way, expected to be available at the end of 2020 .

\section{ㅁ Conclusions}

The history of classification systems and the search for a unified nomenclature in cytopathology spans several decades and expresses the preoccupation of all those involved to increase the utility of cytopathology as a reliable diagnostic method and a trusted screening tool. With the advent of tiered classification systems in cytopathology, more and more performance data (i.e., ROM, predictive values, sensitivities, specificities) was attributed to various diagnostic categories, significantly increasing the reliability of the method. Early classification schemes, applicable to exfoliative and aspiration cytology as well, attempted to set some basic standards as to how nongynecological cytopathology findings should be reported. While useful in establishing some basic guidelines, these were nonetheless not specific to the various fields of nongynecologic cytopathology, often burdened with specific problems.

Most tiered classification systems assign a numeral to each diagnostic category; however, it is not recommended that the diagnosis is conveyed using solely the category number without the accompanying category name or descriptive diagnosis. Omitting the latter two hinders optimal communication between the cytopathologist and the clinician interpreting the report and creates unnecessary confusion and frustration. In all those cases where specific classification systems are not yet in use, some great guidelines exist on how to report non-gynecological cytopathology specimens $[80,81]$.

There is a growing arsenal of molecular markers available that may increase the accuracy of FNA cytology; therefore, cytopathologists need to obtain adequate amounts of material to perform ancillary studies if such is needed.

And then there is the sometimes frustrating (to cytopathologists and clinicians alike) issue of such categories as 'atypical' or 'suspicious' that most, if not all, reporting systems contain. These categories are essential and need to be used, albeit cautiously, to keep other categories safe and sound to provide meaningful clinical information. For instance, in the majority of classification systems, the high negative predictive value of the 'benign' category is maintained by the 'atypical' category. Similarly, the 'suspicious for malignancy' category safeguards the high positive predictive value of the 'malignant' category. In any way, the word 'atypical' should be applied only to lesions that have some significant ROM.

Finally, as humble members of the cytopathology community, we cannot but praise the tremendous effort that the various expert groups, often spanning continents, continuously invest in defining and refining these classification systems to ease the work of cytopathologists and clinicians as well, all for the benefit of the patients. Simultaneously, this endeavor places cytopathology on solid ground to remain one the most trusted morphological disciplines.

\section{Conflict of interests}

The author declares that there is no conflict of interests.

\section{References}

[1] Sundling KE, Kurtycz DFI. Standardized terminology systems in cytopathology. Diagn Cytopathol, 2019, 47(1):53-63. https:// doi.org/10.1002/dc.24103 PMID: 30499199

[2] Juskevicius R, Zou KH, Cibas ES. An analysis of factors that influence the ASCUS/SIL ratio of pathologists. Am J Clin Pathol, 2001, 116(3):331-335. https://doi.org/10.1309/0BL46H9V-DQVV-UGXR PMID: 11554159

[3] Vanderlaan PA, Krane JF, Cibas ES. The frequency of 'atypia of undetermined significance' interpretations for thyroid fineneedle aspirations is negatively correlated with histologically proven malignant outcomes. Acta Cytol, 2011, 55(6):512517. https://doi.org/10.1159/000333231 PMID: 22156459

[4] Chandra S, Chandra H, Bisht SS. Malignancy rate in thyroid nodules categorized as atypia of undetermined significance or 
follicular lesion of undetermined significance - an institutional experience. J Cytol, 2017, 34(3):144-148. https://doi.org/10. 4103/JOC.JOC_234_16 PMID: 28701827 PMCID: PMC5492751

[5] ***. Classes in Oncology: George Nicholas Papanicolaou's new cancer diagnosis presented at the Third Race Betterment Conference, Battle Creek, Michigan, January 2-6, 1928, and published in the Proceedings of the Conference. CA Cancer J Clin, 1973, 23(3):174-179. PMID: 4196138

[6] Papanicolaou GN, Traut HF. The diagnostic value of vaginal smears in carcinoma of the uterus. This study has been aided by the Commonwealth Fund. Presented before the New York Obstetrical Society, March 11, 1941. Am J Obstet Gynecol, 1941, 42(2):193-206. https://doi.org/10.1016/S0002-9378(16) 40621-6

[7] Papanicolaou GN. A new procedure for staining vaginal smears. Science, 1942, 95(2469):438-439. https://doi.org/10.1126/ science.95.2469.438 PMID: 17842594

[8] Babes A. Diagnostic du cancer du col utérin par les frottis. Presse Méd, 1928, 36:451-454.

[9] Koss LG. Aurel Babeş. Int J Gynecol Pathol, 2003, 22(1): 101-102. https://doi.org/10.1097/00004347-200301000-00020 PMID: 12496707

[10] Tasca L, Ostör AG, Babeş V. XII. Aurel Babeş. Int J Gynecol Pathol, 2002, 21(2):198-202. https://doi.org/10.1097/00004 347-200204000-00016 PMID: 11917233

[11] Rylander E. Cervical cancer in women belonging to a cytologically screened population. Acta Obstet Gynecol Scand 1976, 55(4):361-366. https://doi.org/10.3109/00016347609 158514 PMID: 973566

[12] Koss LG. The Papanicolaou test for cervical cancer detection. A triumph and a tragedy. JAMA, 1989, 261(5):737-743. https://doi.org/10.1001/jama.1989.03420050087046 PMID: 2642983

[13] Hoda SA, Hoda RS. Book Review: Introduction to gynecologic cytopathology with histologic and clinical correlations. By L. G. Koss and C. Gompel. Baltimore: Lippincott Williams \& Wilkins, 1999, 202 pp. Int J Gynecol Pathol, 1999, 18(4):404 https://doi.org/10.1097/00004347-199910000-00021

[14] Bogdanich W. Lax Laboratories: the Pap test misses much cervical cancer through labs' errors. The Wall Street Journal, 1987, 210(88):1, 20.

[15] Bogdanich W. Smearing the Pap smear. The Saturday Evening Post, 1988, 260(2):62.

[16] Brophy MA. The Clinical Laboratory Improvement Program: not your ordinary regulatory program. Mil Med, 2000, 165(Suppl 2): 48-51. https://doi.org/10.1093/milmed/165.suppl_2.48 PMID: 10920640

[17] Boone DJ. Literature review of research related to the Clinical Laboratory Improvement Amendments of 1988. Arch Pathol Lab Med, 1992, 116(7):681-693. PMID: 1497439

[18] Ehrmeyer SS, Laessig RH. Effect of legislation (CLIA'88) on setting quality specifications for US laboratories. Scand J Clin Lab Invest, 1999, 59(7):563-567. https://doi.org/10.1080/00 365519950185364 PMID: 10667700

[19] ${ }^{* * *}$. The 1988 Bethesda System for reporting cervical/vaginal cytologic diagnoses. Developed and approved at the National Cancer Institute Workshop, Bethesda, Maryland, U.S.A. December 12-13, 1988. Acta Cytol, 1989, 33(5):567-574. PMID: 2781957

[20] Centers for Disease Control and Prevention (CDC) (2) Centers for Medicare \& Medicaid Services (CMS), HHS. Medicare, Medicaid, and CLIA programs; laboratory requirements relating to quality systems and certain personnel qualifications. Final rule. Fed Regist, 2003, 68(16):3639-3714. PMID: 12545998

[21] Nayar R, Wilbur DC (eds). The Bethesda System for Reporting Cervical Cytology: definitions, criteria, and explanatory notes. $3^{\text {rd }}$ edition, Springer International Publishing, Switzerland, 2015. https://doi.org/10.1007/978-3-319-11074-5

[22] Nayar R, Wilbur DC, Solomon D. Chapter 6 - The Bethesda System for Reporting Cervical Cytology. In: Bibbo M, Wilbur DC (eds). Comprehensive Cytopathology. $3^{\text {rd }}$ edition, Saunders, Elsevier, 2008, 77-90. https://doi.org/10.1016/B978-1-41604208-2.X0041-3

[23] Solomon D, Davey D, Kurman R, Moriarty A, O'Connor D, Prey M, Raab S, Sherman M, Wilbur D, Wright T Jr, Young N; Forum Group Members; Bethesda 2001 Workshop. The 2001 Bethesda System: terminology for reporting results of cervical cytology. JAMA, 2002, 287(16):2114-2119. https://doi.org/ 10.1001/jama.287.16.2114 PMID: 11966386
[24] Kurman RJ, Solomon D (eds). The Bethesda System for Reporting Cervical/Vaginal Cytologic Diagnoses: definitions, criteria, and explanatory notes for terminology and specimen adequacy. Springer Science \& Business Media, 2012.

[25] Nayar R, Wilbur DC. The Bethesda System for reporting cervical cytology: a historical perspective. Acta Cytol, 2017, 61(4-5):359-372. https://doi.org/10.1159/000477556 PMID: 28693017

[26] Sherman ME, Weinstein M, Sughayer M, Cappellari JO, Orr JE, Erozan YS, Schiffman MH, Kurman RJ. The Bethesda System. Impact on reporting cervicovaginal specimens and reproducibility of criteria for assessing endocervical sampling. Acta Cytol, 1993, 37(1):55-60. PMID: 8434497

[27] Sherman ME, Schiffman MH, Erozan YS, Wacholder S, Kurman RJ. The Bethesda System. A proposal for reporting abnormal cervical smears based on the reproducibility of cytopathologic diagnoses. Arch Pathol Lab Med, 1992, 116(11):1155-1158. PMID: 1444745

[28] Lorincz A, Wheeler CM, Arbyn M. Chapter 15 - Triage of women with ASCUS and LSIL abnormal cytology: the ALTS experience and beyond. In: Jenkins D, Bosch FX (eds). Human papillomavirus: proving and using a viral cause for cancer. Academic Press, Elsevier, 2020, 235-243. https://doi.org/10. 1016/B978-0-12-814457-2.00015-5

[29] Cibas ES, Ali SZ. The 2017 Bethesda System for reporting thyroid cytopathology. Thyroid, 2017, 27(11):1341-1346. https://doi.org/10.1089/thy.2017.0500 PMID: 29091573

[30] Baloch Z, LiVolsi VA. The Bethesda System for reporting thyroid cytology (TBSRTC): from look-backs to look-ahead. Diagn Cytopathol, 2020, 48(10):862-866. https://doi.org/10. 1002/dc.24385 PMID: 31999070

[31] Nikiforov YE, Seethala RR, Tallini G, Baloch ZW, Basolo F, Thompson LD, Barletta JA, Wenig BM, Al Ghuzlan A, Kakudo K, Giordano TJ, Alves VA, Khanafshar E, Asa SL, El-Naggar AK, Gooding WE, Hodak SP, Lloyd RV, Maytal G, Mete O, Nikiforova MN, Nosé V, Papotti M, Poller DN, Sadow PM, Tischler AS, Tuttle RM, Wall KB, LiVolsi VA, Randolph GW, Ghossein RA. Nomenclature revision for encapsulated follicular variant of papillary thyroid carcinoma: a paradigm shift to reduce overtreatment of indolent tumors. JAMA Oncol, 2016, 2(8):1023-1029. https://doi.org/10.1001/jamaoncol.2016.0386 PMID: 27078145 PMCID: PMC5539411

[32] Baloch ZW, LiVolsi VA, Asa SL, Rosai J, Merino MJ, Randolph G, Vielh P, DeMay RM, Sidawy MK, Frable WJ. Diagnostic terminology and morphologic criteria for cytologic diagnosis of thyroid lesions: a synopsis of the National Cancer Institute Thyroid Fine-Needle Aspiration State of the Science Conference. Diagn Cytopathol, 2008, 36(6):425-437. https://doi.org/10.10 02/dc.20830 PMID: 18478609

[33] Ali SZ, Cibas E (eds). The Bethesda System for Reporting Thyroid Cytopathology: definitions, criteria and explanatory notes. Springer Science \& Business Media, 2010. https://doi. org/10.1007/978-0-387-87666-5

[34] Young RH, Eble JN. The history of urologic pathology: an overview. Histopathology, 2019, 74(1):184-212. https://doi.org/ 10.1111/his.13753 PMID: 30565309

[35] Murphy WM, Soloway MS, Jukkola AF, Crabtree WN, Ford KS. Urinary cytology and bladder cancer. The cellular features of transitional cell neoplasms. Cancer, 1984, 53(7):1555-1565. https://doi.org/10.1002/1097-0142(19840401)53:7<1555::aidcncr2820530723>3.0.co;2-g PMID: 6697294

[36] Ooms EC, Veldhuizen RW. Cytological criteria and diagnostic terminology in urinary cytology. Cytopathology, 1993, 4(1):5154. https://doi.org/10.1111/j.1365-2303.1993.tb00073.x PMID: 8453017

[37] Owens CL, Vandenbussche CJ, Burroughs FH, Rosenthal DL. A review of reporting systems and terminology for urine cytology. Cancer Cytopathol, 2013, 121(1):9-14. https://doi.org/10.1002/ cncy.21253 PMID: 23192885

[38] Koh HH, Lee MJ, Park NJ, Kim HS, Oh YL. Impact of implementing the Paris System for Reporting Urinary Cytology: a single-institutional experience with emphasis on diagnostic yield of high-grade urothelial carcinoma and low-grade urothelial neoplasm. Anticancer Res, 2020, 40(6):3477-3484. https:// doi.org/10.21873/anticanres.14334 PMID: 32487647

[39] Mclntire PJ, Khan R, Hussain H, Pambuccian SE, Wojcik EM, Barkan GA. Negative predictive value and sensitivity of urine cytology prior to implementation of the Paris System for Reporting Urinary Cytology. Cancer Cytopathol, 2019, 127(2): 125-131. https://doi.org/10.1002/cncy.22102 PMID: 30668891 
[40] Barkan GA, Tabatabai ZL, Kurtycz DFI, Padmanabhan V, Souers RJ, Nayar R, Sturgis CD. Practice patterns in urinary cytopathology prior to the Paris System for Reporting Urinary Cytology. Arch Pathol Lab Med, 2020, 144(2):172-176. https:// doi.org/10.5858/arpa.2019-0045-CP PMID: 31295017

[41] Barkan GA, Wojcik EM, Nayar R, Savic-Prince S, Quek ML, Kurtycz DF, Rosenthal DL. The Paris System for Reporting Urinary Cytology: the quest to develop a standardized terminology. Acta Cytol, 2016, 60(3):185-197. https://doi.org/10. 1159/000446270 PMID: 27318895

[42] VandenBussche CJ. A review of the Paris System for Reporting Urinary Cytology. Cytopathology, 2016, 27(3):153-156. https:// doi.org/10.1111/cyt.12345 PMID: 27221750

[43] Rosenthal DL, Wojcik EM, Kurtycz DFI (eds). The Paris System for Reporting Urinary Cytology. Springer International Publishing, Switzerland, 2016. https://doi.org/10.1007/978-3-319-22864-8

[44] Bigorgne C, Vielh P, Courtade-Saidi M; Société Française de Cytologie Clinique. [Salivary gland cytopathology: Milan System 2018]. Ann Pathol, 2020, 40(1):46-58. https://doi.org/10.10 16/j.annpat.2019.12.001 PMID: 31917017

[45] Rossi ED, Faquin WC, Baloch Z, Barkan GA, Foschini MP Pusztaszeri M, Vielh P, Kurtycz DFI. The Milan System for Reporting Salivary Gland Cytopathology: analysis and suggestions of initial survey. Cancer Cytopathol, 2017 125(10):757-766. https://doi.org/10.1002/cncy.21898 PMID: 28708928

[46] Tyagi R, Dey P. Diagnostic problems of salivary gland tumors. Diagn Cytopathol, 2015, 43(6):495-509. https://doi.org/10. 1002/dc.23255 PMID: 25614439

[47] Schmidt RL, Narra KK, Witt BL, Factor RE. Diagnostic accuracy studies of fine-needle aspiration show wide variation in reporting of study population characteristics: implications for external validity. Arch Pathol Lab Med, 2014, 138(1):88-97. https:// doi.org/10.5858/arpa.2013-0036-OA PMID: 24377815

[48] Griffith CC, Pai RK, Schneider F, Duvvuri U, Ferris RL, Johnson JT, Seethala RR. Salivary gland tumor fine-needle aspiration cytology: a proposal for a risk stratification classification. Am J Clin Pathol, 2015, 143(6):839-853. https://doi. org/10.1309/AJCPMII6OSD2HSJA PMID: 25972326 PMCID: PMC5257286

[49] Rossi ED, Wong LQ, Bizzarro T, Petrone G, Mule A, Fadda G, Baloch ZM. The impact of FNAC in the management of salivary gland lesions: institutional experiences leading to a risk-based classification scheme. Cancer Cytopathol, 2016 124(6):388-396. https://doi.org/10.1002/cncy.21710 PMID: 26959289

[50] Wei S, Layfield LJ, LiVolsi VA, Montone KT, Baloch ZW. Reporting of fine needle aspiration (FNA) specimens of salivary gland lesions: a comprehensive review. Diagn Cytopathol, 2017, 45(9):820-827. https://doi.org/10.1002/dc.23716 PMID: 28371507

[51] Rossi ED, Baloch ZW, Pusztaszeri M, Faquin WC. The Milan System for Reporting Salivary Gland Cytopathology (MSRSGC): an ASC-IAC-sponsored system for reporting salivary gland fineneedle aspiration. Acta Cytol, 2018, 62(3):157-165. https:// doi.org/10.1159/000488969

[52] Pusztaszeri M, Baloch Z, Vielh P, Faquin WC. Application of the Milan System for reporting risk stratification in salivary gland cytopathology. Cancer Cytopathol, 2018, 126(1):69-70. https://doi.org/10.1002/cncy.21945 PMID: 29165894

[53] Faquin WC, Rossi ED, Baloch Z, Barkan GA, Foschini M, Kurtycz DFI, Pusztaszeri M, Vielh P (eds). The Milan System for Reporting Salivary Gland Cytopathology. Springer International Publishing AG, 2018. https://doi.org/10.1007/978-3319-71285-7

[54] Wu HH, Alruwaii F, Zeng BR, Cramer HM, Lai CR, Hang JF. Application of the Milan System for Reporting Salivary Gland Cytopathology: a retrospective 12-year bi-institutional study. Am J Clin Pathol, 2019, 151(6):613-621. https://doi.org/10. 1093/ajcp/aqz006 PMID: 30852595

[55] Farahani SJ, Baloch Z. Retrospective assessment of the effectiveness of the Milan System for Reporting Salivary Gland Cytology: a systematic review and meta-analysis of published literature. Diagn Cytopathol, 2019, 47(2):67-87. https://doi. org/10.1002/dc.24097 PMID: 30375201

[56] Lee JJL, Tan HM, Chua DYS, Chung JGK, Nga ME. The Milan System for Reporting Salivary Gland Cytology: a retrospective analysis of 1384 cases in a tertiary Southeast Asian institution. Cancer Cytopathol, 2020, 128(5):348-358. https://doi.org/10. 1002/cncy.22245 PMID: 32022995
[57] Chen YA, Wu CY, Yang CS. Application of the Milan System for Reporting Salivary Gland Cytopathology: a retrospective study in a tertiary institute. Diagn Cytopathol, 2019, 47(11):11601167. https://doi.org/10.1002/dc.24279 PMID: 31313521

[58] Jalaly JB, Farahani SJ, Baloch ZW. The Milan System for Reporting Salivary Gland Cytopathology: a comprehensive review of the literature. Diagn Cytopathol, 2020, 48(10):880 889. https://doi.org/10.1002/dc.24536 PMID: 32640095

[59] Barbarite E, Puram SV, Derakhshan A, Rossi ED, Faquin WC, Varvares MA. A call for universal acceptance of the Milan System for Reporting Salivary Gland Cytopathology. Laryngoscope, 2020, 130(1):80-85. https://doi.org/10.1002/lary.27905 PMID: 30848480 PMCID: PMC7404613

[60] Vallonthaiel AG, Kaushal S, Jangir H, Rajendran HK. Application of the Milan System for risk stratification and its comparison with a previous reporting system of parotid gland cytopathology in a tertiary care centre. Acta Cytol, 2018, 62(5-6):352-359. https://doi.org/10.1159/000492051 PMID: 30223278

[61] Pitman MB, Centeno BA, Ali SZ, Genevay M, Stelow E, MinoKenudson M, Castillo CF, Schmidt CM, Brugge WR, Layfield LJ. Standardized terminology and nomenclature for pancreatobiliary cytology: the Papanicolaou Society of Cytopathology Guidelines. Cytojournal, 2014, 11(Suppl 1):3. https://doi.org/ 10.4103/1742-6413.133343 PMID: 25191517 PMCID: PMC 4153338

[62] Pitman MB, Layfield LJ. The Papanicolaou Society of Cytopathology System for Reporting Pancreaticobiliary Cytology: definitions, criteria, and explanatory notes. Springer International Publishing, Switzerland, 2015. https://doi.org/10.1007/9783-319-16589-9

[63] Layfield LJ, Baloch Z, Elsheikh T, Litzky L, Rekhtman N, Travis WD, Zakowski M, Zarka M, Geisinger K. Standardized terminology and nomenclature for respiratory cytology: the Papanicolaou Society of Cytopathology Guidelines. Diagn Cytopathol, 2016, 44(5):399-409. https://doi.org/10.1002/dc. 23457 PMID: 26990836

[64] Layfield LJ, Roy-Chowdhuri S, Baloch Z, Ehya H, Geisinger K, Hsiao SJ, Lin O, Lindeman NI, Roh M, Schmitt F, Sidiropoulos N, VanderLaan PA. Utilization of ancillary studies in the cytologic diagnosis of respiratory lesions: the Papanicolaou Society of Cytopathology consensus recommendations for respiratory cytology. Diagn Cytopathol 2016, 44(12):1000-1009. https:// doi.org/10.1002/dc.23549 PMID: 27561242 PMCID: PMC 5590370

[65] Yung RCW, Otell S, Illei P, Clark DP, Feller-Kopman D, Yarmus L, Askin F, Gabrielson E, Li QK. Improvement of cellularity on cell block preparations using the so-called tissue coagulum clot method during endobronchial ultrasound-guided transbronchial fine-needle aspiration. Cancer Cytopathol, 2012, 120(3):185-195. https://doi.org/10.1002/cncy.20199 PMID: 22144401 PMCID: PMC4596239

[66] Stoll LM, Yung RCW, Clark DP, Li QK. Cytology of endobronchial ultrasound-guided transbronchial needle aspiration versus conventional transbronchial needle aspiration. Cancer Cytopathol, 2010, 118(5):278-286. https://doi.org/10.1002/ cncy.20103 PMID: 20740503

[67] Layfield LJ, Dodd L, Witt B. Malignancy risk for the categories: non-diagnostic, benign, atypical, suspicious, and malignant used in the categorization of endobronchial ultrasound guided-fine needle aspirates of pulmonary nodules. Diagn Cytopathol, 2015, 43(11):892-896. https://doi.org/10.1002/dc.23326 PMID: 26331778

[68] Lilo MT, Allison DB, Younes BK, Cui M, Askin FB, Gabrielson E, Li QK. The critical role of EBUS-TBNA cytology in the staging of mediastinal lymph nodes in lung cancer patients: a correlation study with positron emission tomography findings. Cancer Cytopathol, 2017, 125(9):717-725. https://doi.org/10.1002/cncy. 21886 PMID: 28609021

[69] Travis WD, Brambilla E, Burke AP, Marx A, Nicholson AG (eds). World Health Organization (WHO) Classification of Tumours of the lung, pleura, thymus and heart. WHO Classification of Tumours, International Agency for Research on Cancer (IARC) Press, Lyon, France, 2015

[70] Layfield LJ, Baloch Z (eds). The Papanicolaou Society of Cytopathology System for Reporting Respiratory Cytology: definitions, criteria, explanatory notes, and recommendations for ancillary testing. Springer Nature Switzerland AG, 2019. https://doi.org/10.1007/978-3-319-97235-0 
[71] Li JJX, Tse GM. Core needle biopsy diagnosis of fibroepithelia lesions of the breast: a diagnostic challenge. Pathology, 2020, 52(6):627-634. https://doi.org/10.1016/j.pathol.2020.06.005 PMID: 32771211

[72] Dupain C, Masliah-Planchon J, Gu C, Girard E, Gestraud P, Du Rusquec P, Borcoman E, Bello D, Ricci F, Hescot S, Sablin MP, Tresca P, de Moura A, Loirat D, Frelaut M, VincentSalomon A, Lecerf C, Callens C, Antonio S, Franck C, Mariani O, Bièche I, Kamal M, Le Tourneau C, Servois V. Fine-needle aspiration as an alternative to core needle biopsy for tumour molecular profiling in precision oncology: prospective comparative study of next-generation sequencing in cancer patients included in the SHIVA02 trial. Mol Oncol, 2021, 15(1):104-115. https:// doi.org/10.1002/1878-0261.12776 PMID: 32750212 PMCID: PMC7782085

[73] De Rosa F, Migliatico I, Vigliar E, Salatiello M, Pisapia P, laccarino A, Russo D, Insabato L, Accurso A, Arpino G, Palombini L, Troncone G, Bellevicine C. The continuing role of breast fine-needle aspiration biopsy after the introduction of the IAC Yokohama System for Reporting Breast Fine Needle Aspiration Biopsy Cytopathology. Diagn Cytopathol, 2020, 48(12):1244-1253. https://doi.org/10.1002/dc.24559 PMID: 32749785

[74] Field AS, Schmitt F, Vielh P. IAC Standardized Reporting of Breast Fine-Needle Aspiration Biopsy Cytology. Acta Cytol, 2017, 61(1):3-6. https://doi.org/10.1159/000450880 PMID: 27806362

[75] Field AS, Raymond WA, Schmitt F (eds). The International Academy of Cytology Yokohama System for Reporting Breast Fine Needle Aspiration Biopsy Cytopathology. Springer Nature Switzerland AG, 2020. https://doi.org/10.1007/978-3-030-26 883-1
[76] Chandra A, Crothers B, Kurtycz D, Schmitt F. Announcement: the International System for Reporting Serous Fluid Cytopathology. Acta Cytol, 2019, 63(5):349-351. https://doi.org/ 10.1159/000501536 PMID: 31234178

[77] Rodriguez EF, Jones R, Gabrielson M, Santos D, Pastorello RG, Maleki Z. Application of the International System for Reporting Serous Fluid Cytopathology (ISRSFC) on reporting pericardial effusion cytology. Acta Cytol, 2020, 64(5):477-485. https:// doi.org/10.1159/000507311 PMID: 32422631

[78] Pinto D, Chandra A, Crothers BA, Kurtycz DFI, Schmitt F. The International System for Reporting Serous Fluid Cytopathology - diagnostic categories and clinical management. J Am Soc Cytopathol, 2020, 9(6):469-477. https://doi.org/10. 1016/j.jasc.2020.05.015 PMID: 32620534

[79] Lobo C, Costa J, Petronilho S, Monteiro P, Leça L, Schmitt F. Cytohistological correlation in serous effusions using the newly proposed International System for Reporting Serous Fluid Cytopathology: experience of an oncological center. Diagn Cytopathol, 2020 Apr 27. https://doi.org/10.1002/dc.24440 PMID: 32339444

[80] Crothers BA, Tench WD, Schwartz MR, Bentz JS, Moriarty AT, Clayton AC, Fatheree LA, Chmara BA, Wilbur DC. Guidelines for the reporting of nongynecologic cytopathology specimens. Arch Pathol Lab Med, 2009, 133(11):1743-1756. https://doi. org/10.1043/1543-2165-133.11.1743 PMID: 19886707

[81] Chandra A, Cross P, Denton K, Giles T, Hemming D, Payne C, Wilson A, Wilson P. The BSCC code of practice - exfoliative cytopathology (excluding gynaecological cytopathology). Cytopathology, 2009, 20(4):211-223. https://doi.org/10.1111/ j.1365-2303.2009.00679.x PMID: 19659955

\section{Corresponding author}

Tibor Mezei, Lecturer, MD, PhD, Department of Pathology, George Emil Palade University of Medicine, Pharmacy, Science, and Technology of Târgu Mureş, 38 Gheorghe Marinescu Street, 540142 Târgu Mureş, Romania; Phone +40744-429 295, e-mail: tmezei@pathologia.ro 